\title{
Reuse of Paper Mill Ash in Plaster Blends
}

\author{
Saveria Monosi, Daniela Sani* and Maria Letizia Ruello
}

\begin{abstract}
Università Politecnica delle Marche - Dipartimento di Scienze e Ingegneria della Materia, dell'Ambiente ed Urbanistica (SIMAU), Italy
\end{abstract}

\begin{abstract}
This work is part of a broad research conducted to study the re-use of industrial wastes in an economical and environmentally sustainable manner. Re-use of lightweight ash from the paper mill industry in the manufacture of plaster blends is examined in this study. Lightweight ash is produced during the combustion process of de-inking sludge. Studies demonstrate that lightweight ash is an excellent ingredient in the production of cement mortars and/or pozzolanic mortars to be used as plaster. In this research, ash valorization was researched by investigating the efficacy of the ash as it is, as a substitute for very fine sand.

If properly mixed at an optimal mix proportion, the mechanical strength ranges from $4 \div 10 \mathrm{MPa}$ with specific gravity between 1150 and $1350 \mathrm{Kg} / \mathrm{m}^{3}$. Water absorption may be reduced to a very low level with silane-based surface treatment.
\end{abstract}

Keywords: Paper mill ash, de-inking ash, plaster, mortar, aggregate replacing, permeability, water absorption, compressive strength.

\section{INTRODUCTION}

This study was developed as part of a broader research aimed to demonstrate the technical, environmental and economical benefits of recycling an industrial by-product such as paper mill fly ash.

According to the European Commission's "Strategy on the prevention and recycling of waste" [1], the main thrust of their strategy lies in amending the legislation to improve its implementation and in preventing waste and promoting effective recycling. Parallel to these political aspects, setting out guidelines and describing measures aimed at reducing pressure on the environment caused by waste production and management, new researches and aspects of innovation must be pursued in order to put the strategy into practice.

Following this topic, the present paper deals with an industrial research that identifies new market applications for paper mill by-products as additives or ingredients in construction materials. Re-use of lightweight ash in the manufacture of plaster blends is examined in this study.

Lightweight ash comes from the combustion of paper mill sludge. In turn, the sludge is a by-product of the pulp and paper industry as well as paper recycling mills. If properly managed, paper by-products (such as ash and sludge) represent a typical example of industrial symbiosis [2] where all resources (materials, energy, water, etc...) fulfil a specific role in the industrial process. Once used, these materials should be salvaged and if necessary, modified or reprocessed to be reused elsewhere. As such, resources can be used again in other sectors (i.e., the construction sector). Despite the potential and the metaphor of the natural

*Address correspondence to this author at the Università Politecnica delle Marche, Department of Physic and Engineering of Materials, Italy; Tel: +39 071 2204726; Fax: +39 071 2204627;

E-mails: d.sani@univpm.it; monosi@univpm.it eco-system [2], the eco-efficient utilization of pulp mill byproducts presupposes to identify new final destinations that are more market attractive and environmentally friendly. Literature examples of industrial symbiosis applied to the overall processes of the paper mill industry are available in open journals and books.

In the Italian contest, where the paper industry has a long tradition and competitive clustering, de-inking sludge is an increasing as well as promising waste typology resulting from the separate collection of industrial solid waste [3, 4]. An average of $6 \mathrm{~kg}$ of sludge is produced from every ton of paper. In 2004, the total Italian production was about $6 \cdot 10^{5}$ tons [5]. Historically, paper mill sludge has been used as landfill or as potential soil amendment and forest fertilizer [6-9]. The practice of employing fertilizer requires a better knowledge of and strict control over an undesired release of contaminants (especially metals) into the environment [6]. Only in few sporadic cases they have been used in the production of bricks [10-12].

On the other hand, landfill disposal has raised costs and difficulties in acquiring new sites due to environmental conservation regulations. Moreover, landfilling is a waste of resources because paper sludge is a readily recyclable product and useful material.

At the Center for By-Products Utilization of the University of Wisconsin-Milwauke (Milwaukee, USA), researchers have proposed to reuse it in the manufacture of [13-15]:

- dry-cast concrete products such as masonry blocks and paving stones;

- $\quad$ wet-cast precast products;

- $\quad$ structural-grade concrete;

- and in controlled low-strength materials (CLSMs), also called flowable slurry or flowable fill, that are 
low-strength concrete-like material for non-structural use.

Other final destinations of paper mill sludge are in the paper industry itself when co-burnt with wood residue for producing heat and power for internal use. In that case, it could be more widely used as combustion material in a combined heat and power plant (CHP), according to the European Directives 2004/8 on Co-generation and 2008/98 on wastes [16]. These combustion residues are commonly classified as fly ashes as they come from the air emission control systems of the plants. The recent policy that sustains the use of bio-fuels (the 20-20-20 Europe targets [17]) is increasing the annual amount of fly ash produced in Europe, more than just paper industry.

According to existing experimentation, in the overall product life cycle, ashes from the combustion processes of paper mills are collected and recycled as a new by-product. They can be mostly reused as materials for the construction sector [18]. At the Institute National de Sciences Appliqués (INSA, Lyon, France), researchers have developed a calcination process to make them more pozzolanic and therefore more performing in concrete applications [19]. The calcination process increases the market value of ashes. Other attempts have been made to produce cements [20] and self-compacting concrete [21].

However, industrial applications of paper ash need further investigation and innovation in order to become more market attractive and environmentally friendly. According to the (revised) European Waste Framework Directive [22], the paper objectives follow the waste hierarchy and focus on both waste reduction and recycling. In fact, the study aims to:

- $\quad$ reduce the use of natural resources (like natural sand) and reduce the amount of waste in the paper mill industry by identifying new final destinations for wastes;

- recycle paper mill ash without any additional processing, that is without any additional cost.

Moreover, the Directive also aims to demonstrate that paper mill ash could be a performing ingredient in the production of mortars and plasters, although it is rather far from being an industrialized solution in its original state ("as it is").

The performance of interior/exterior plasters mainly depends on the properties of the mixed material (both sand and binder), the thickness of the layers and its application. Depending on the kind of application, it is possible to design a proper plaster by getting special properties based on the type of aggregates, admixtures and/or mineral additions used.

Frequently, the plaster selection is based on the external surface appearance; thus innovation in plaster design should be aimed to improve surface finishing. Paper ashes quite often exhibit lighter and finer properties as well as cheaper peculiarities than traditional ingredients: these properties should deal with improving surface finishing.

In this work, the ashes were provided by "Burgo Group" paper mills (Mantova, Italy). They were obtained from the combustion process of de-inking sludge. The initial composition of the sludge was up to $55 \%$ of dry matter along with water. As far as the paper ash composition is concerned, it was mainly calcium silicates and oxides in addition to magnesium and aluminium oxides. They are classified as non-hazardous special waste and can therefore be disposed of in type B landfills according to Italian regulations [23, 24]. Similarly, such classification is expressed under EU and USA rules [21, 25].

\section{MATERIALS AND METHODS}

In the experimental stage, the following materials were used:

- $\quad$ paper mill ash;

- $\quad$ Portland cement type CEMII AL 42.5R (according to EN-197/1);

- $\quad$ limestone powder (calcium carbonate);

- natural sand with a maximum diameter of $2 \mathrm{~mm}$ (according to EN 1097-6 and EN 933-1);

- $\quad$ and a silane-based hydrophobic product.

The paper ash, provided by "Burgo Group" paper mills (Mantova, Italy), comes from a traditional process of coated paper, more precisely from the combustion process of deinking sludge. Paper wastes from the local productive plant were mostly employed in combustion. The main elements of the paper ash composition were:

$$
\begin{array}{ll}
\text { - } & \text { silica oxide }(30-40 \%) ; \\
\text { - } & \text { calcium oxide }(30-40 \%) ; \\
\text { - } & \text { aluminium and magnesium oxides. }
\end{array}
$$

The first phase involved the characterization of the paper ash in terms of its mineral composition (as mentioned above), bulk density of the dry powder, particle size distribution and surface analysis.

The bulk density of the paper ash, equal to $1200 \mathrm{~kg} / \mathrm{m}^{3}$, was lighter than ordinary sand (that conventionally ranges from 2500 to $2600 \mathrm{~kg} / \mathrm{m}^{3}$ ) and binders $\left(2100-3100 \mathrm{~kg} / \mathrm{m}^{3}\right)$ generally used in the manufacture of mortars. Particle size distribution by using lazer granulometer (DigiSizer 5200) is reported in Fig. (1).

Ash particles were below $250 \mu \mathrm{m}$, such as the finer fractions of sand; at least $50 \%$ of them were below $80 \mu \mathrm{m}$, which is the typical size of binders and fillers.

This fineness and lightness raise the use of paper ash as the only aggregate in plasters, promising a good surface finishing to plasters.

The shape and surface texture of particles were observed by a Scanning Electron Microscope (SEM).

Shape and texture were evaluated because of their influence on mortar mixture consistency and on water requirement. Results (see Fig. 2) detected high open particle porosity, which is the first indicator of the amount of water required to saturate it. The total water amount needed to be properly taken into account during the optimization of the mix design.

Mixtures of Portland cement - type CEMII AL 42.5R lime and paper ash were prepared to reproduce plasters. 


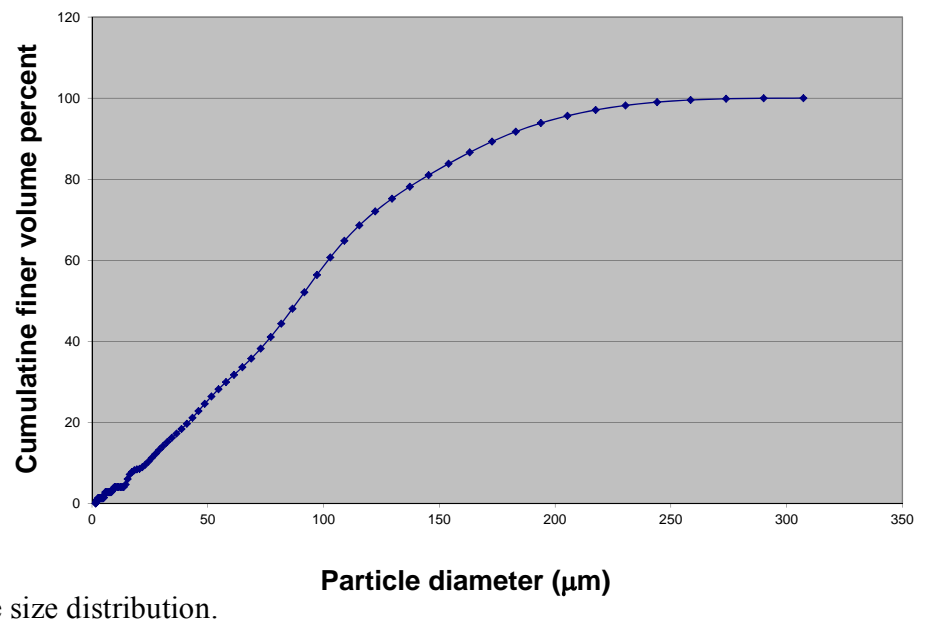

Fig. (1). Paper fly ash particle size distribution.

Several proportions of mixtures were made varying the Table 1 shows the characteristics of the mixed mortars produced.
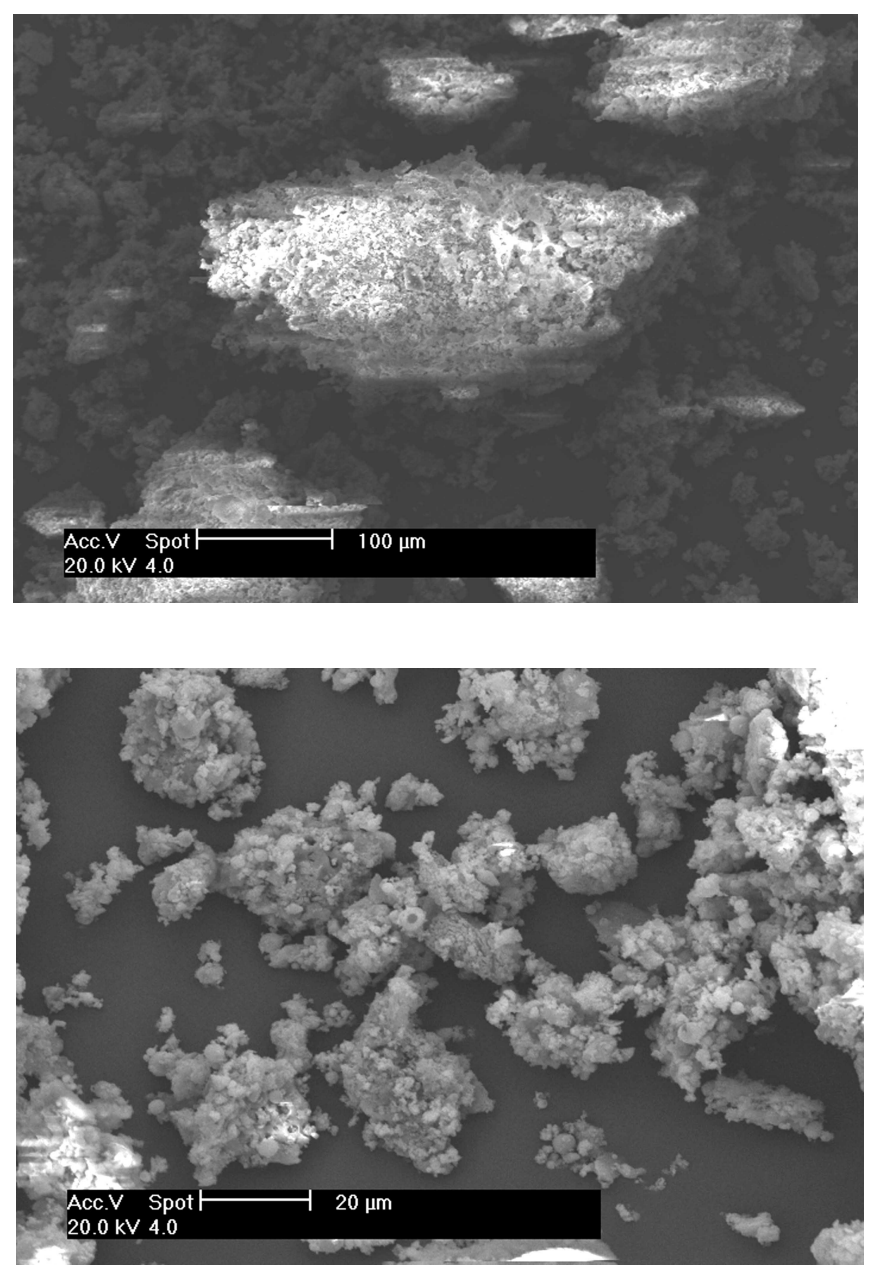

Fig. (2). Paper fly ash observed under a SEM at two different spots $(20 \mu \mathrm{m}$ and $100 \mu \mathrm{m})$.

A conventional plaster mixture composition without paper ash or other inert materials (M0 in Table 1) were considered as reference in terms of water-binder ratio and specific weight. ratio of paper ash and binder ( $\mathrm{pa} / \mathrm{b}$ in Table 1$)$, namely $\mathrm{M} 1$, M2 and M3. In some mixture proportions, namely M4 and M5 (Table 1), natural sand was used to partly replace paper ash in order to obtain a proper mixture for several plaster types.

Table 1. Characteristics of Mortar Mixes

\begin{tabular}{|c|c|c|c|c|}
\hline Mortars & $\mathbf{p a / b}[-]$ & $\mathbf{w} / \mathbf{b}[-]$ & $\mathbf{s f}[\mathrm{mm}]$ & $\mathrm{sw}\left[\mathrm{Kg} / \mathrm{m}^{3}\right]$ \\
\hline M0 & - & 0.61 & 145 & 1240 \\
\hline M1 & $1 / 1$ & 1.7 & 150 & 1265 \\
\hline M2 & $2 / 1$ & 2.27 & 135 & 1215 \\
\hline M3 & $3 / 1$ & 3.5 & 125 & 1165 \\
\hline M4 & $1 / 1$ & 1.56 & 140 & 1370 \\
\hline M5 & $1.5 / 1$ & 2.1 & 145 & 1352 \\
\hline M6 & $2 / 1$ & 2.24 & 140 & 1262 \\
\hline M7 & $2 / 0.5$ & 2.20 & 130 & 1225 \\
\hline M8 & $3 / 0.5$ & 3.16 & 135 & 1177 \\
\hline \multicolumn{5}{|c|}{ 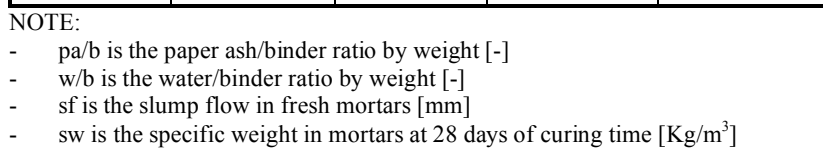 } \\
\hline
\end{tabular}

In all these mixtures (from M1 to M5), a conventional binder, made of lime and cement with equal weight $(50 \%$ cement, 50\% lime), was used.

In addition, carbon fly ash and calcium carbonate were used as partial substitution of the main binder. In these cases the composition was modified:

- $\quad$ the first consisted in replacing the cement with carbon fly ash (M6) - traditionally well known as material with good pozzolanic properties;

- $\quad$ the second consisted in replacing lime with limestone powder, i.e., calcium carbonate (M7, M8).

A hydrophobic product was used as surface treatment in some selected specimens (Table $\mathbf{3}$ ). 
The water/binder $(\mathrm{w} / \mathrm{b})$ ratio reported in Table $\mathbf{1}$ is very high because of the fineness of the paper ash rate and because it comprises water "surplus". Water surplus is defined as the water necessary to fully saturate the open porosity of paper ash as previously specified. This aspect is not negligible due to the high porosity of paper ash showed by SEM detection. The surplus estimated an average value of $40 \% \pm 2$ by weight of dry paper ash.

The mortars were characterized in both fresh and hardened conditions by means of respectively the workability at the flow table (UNI EN 1015-3: 2000) and the mechanical properties at 28 days of curing time. Mechanical properties consist of compressive strength (UNI EN 101511:2001).

Capillary water absorption (UNI EN 1015-18: 2004) and water vapor transmission (UNI EN 1015-19: 2008) were also measured in order to better characterize the most common properties of the plasters.

Experimental stage was performed on prismatic specimens $(40 \times 40 \times 160 \mathrm{~mm})$. At least 2 samples for each mixture were tested, according to the standard requirement aforementioned. The values of the results represent the average of these multiple tests.

\section{RESULTS AND DISCUSSION}

The measured workability was quite scattered ranging between $125 \mathrm{~mm}$ and $150 \mathrm{~mm}$ (see figures in Table 1). To meet workability values, as recommended by the UNI-EN 1015 guidelines (slump flow $\geq 150 \mathrm{~mm}$ ), small adjustments should be requested. As such, any adjustment (water addition or plasticizer admixture) was not made because the workability obtained was considered to be close to that required for most traditional applications (handcraft application). Moreover, the modification in the water/binder ratio led to a change in the performance of the hardened material. Alternatively, an aware amount of plasticizer admixture can be added to adjust only workability, but paying great attention to avoid bleeding effects. However, investigation in greater detail is necessary to find the best compromise.

The specific weight, less than $1300 \mathrm{Kg} / \mathrm{m}^{3}$, allows us to classify most of the mixtures created as light mortars.

The mechanical characteristics (see Table 2) turned out to be within a range of values that fit with almost all classes of resistance provided by traditional mortars. In fact, compressive strength values $>3.5 \mathrm{MPa}$ are mostly used in several operative conditions. Recommended operative conditions versus compressive strength are available in the table of the UNI EN 998-1:2004 annex.

Scattering in the strength range could be mainly ascribed to several factors or to a combination of the following:

- the paper ash/binder ratio (which was changed as reported in Table 1, see M1, M2, M3);

- $\quad$ the partial replacement of paper ash with natural sand by $50 \%$ in weight (see in particular mortar M4 and M5 in Table 1);

- $\quad$ changing the binder (in M6 by replacing cement with carbon fly ash, mineral admixture with good pozzolanic properties, while replacing lime with limestone powder, inert material, in M7 and M8).

In order to satisfy different mechanical requirements, it is certainly possible to extend the range of values obtained by making changes in the proportions of the mortars. This also fits with workability adjustment. According to the authors' suggestions, by adjusting the type of binder and the ratio paper ash/binder, the mechanical properties can joint to requirements. Similar conclusions have also been suggested by Fava et al. [26].

Water absorption coefficient (wa) was not negligible due to the high porosity of the mortars. It could be reduced to more negligible values by treating the surface of the mortar with hydrophobic products. In fact, a commercial silane hydrophobic product was used to treat the surface of some specimens after which the water absorption coefficient was newly calculated and later reported in Table $\mathbf{3}$. As expected, new water absorption values compared with those of Table 2 , show a reduced water absorption coefficient. Therefore, such plasters with a negligible water absorption characteristic could be strongly recommended for external applications, i.e., surface exposed to weathering conditions. Because hydrophobic additive deteriorates with time, it should be periodically (indicatively every 4-5 years) renewed in order to avoid water absorption and plaster deterioration.

Table 2. Compressive Strength (Rc) and Water Absorption Coefficient (wa) of Mortars

\begin{tabular}{|c|c|c|}
\hline Mortars & Rc $[\mathbf{M P a}]$ & wa $\left[\mathbf{K g} /\left(\mathbf{m}^{\mathbf{2}} \cdot \mathbf{m i n}^{\mathbf{0 . 5}}\right)\right]$ \\
\hline \hline M1 & 9.5 & 3.6 \\
\hline M2 & 7 & 4.9 \\
\hline M3 & 5 & 7.5 \\
\hline M4 & 8 & 7.4 \\
\hline M5 & 7 & 5.8 \\
\hline M6 & 4 & 4.9 \\
\hline M7 & 5.5 & 9.5 \\
\hline M8 & 4 & 11.2 \\
\hline
\end{tabular}

Table 3. Water Absorption Coefficient of Mortars without (wa) and with Hydrophobic (wa_h) Admixture

\begin{tabular}{|c|c|c|}
\hline Mortars & wa $\left[\mathbf{K g} /\left(\mathbf{m}^{\mathbf{2}} \cdot \mathbf{m i n}^{\mathbf{0 . 5}}\right)\right]$ & wa_h $\left[\mathbf{K g} /\left(\mathbf{m}^{\mathbf{2}} \cdot \mathbf{m} \mathbf{m i n}^{\mathbf{0 . 5}}\right)\right]$ \\
\hline \hline M2 & 4.9 & 0.03 \\
\hline M3 & 7.5 & 0.09 \\
\hline M6 & 4.9 & 0.02 \\
\hline M7 & 9.5 & 0.08 \\
\hline M8 & 11.2 & 0.06 \\
\hline
\end{tabular}

Results of water vapor transmission are showed in Figs. (3-5), namely mortars M2, M3, M6, M7 and M8. These mortars are characterized by the absence of natural sand and high paper ash content. The absence of natural sand simplifies the testing model (i.e., the transition area between 
binder and inert is avoided) and enhances the effect of paper ash on water vapor transmission.

Fig. (3) compares water vapor transmission trends of two mortars having same binder (cement + lime) but different paper ash/binder ratio. Fig. (3) shows that the presence of a higher amount of paper ash increases vapor transmission, which is expressed as specimen weight loss by evaporation.

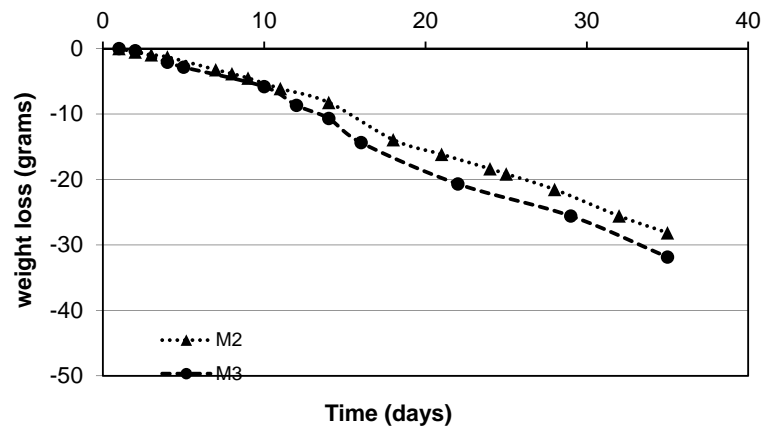

Fig. (3). Water vapor transmission in mortars having different paper ash/binder ratio $(\mathrm{pa} / \mathrm{b})$, in presence of cement + lime binder.

As previously outlined by capillary water absorption (see also water absorption coefficient in Table $\mathbf{3}$ ), it is confirmed that paper ash in mortars increases open porosity. Both high permeability and porosity drive in the characteristic of plaster breathability. On the other hand, also trends in Fig. (4) confirm the effect of the breathability of paper ash mortars. In this case, the binder is cement alone, and lime is replaced by limestone powder. The characteristic of breathability is mainly due to paper ash (see trend with higher paper ash and cement ratio) as any other ingredient is introduced into the specimen.

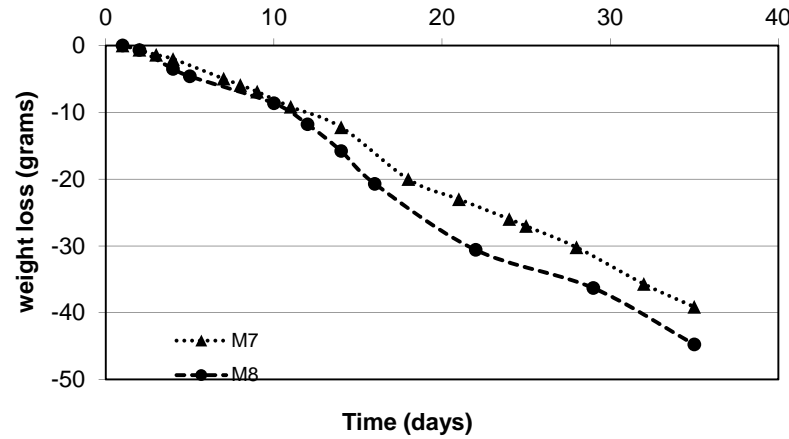

Fig. (4). Water vapor transmission in mortars having different paper $\mathrm{ash} / \mathrm{binder}$ ratio $(\mathrm{pa} / \mathrm{b})$, in presence of cement alone.

Lastly, in Fig. (5), a comparison of the permeability of the mortars, prepared with the same amount of binder but of different nature, confirms the increased permeability of pozzolanic mortars (lime-carbon fly ash) compared to those with cement and lime.

As far as the water vapor transmission properties are concerned, their results are listed in Table 4. Values of water vapor transmission - expressed as resistance to vapor transmission $(\mu)$ - range between the low limits of 5 and 7 . According to the table, the obtained values are quite close or point out only slightly differences. This is mainly due to the subsequent approximations in the numerical calculation of the water vapor transmission. In fact, a more revealing difference is showed in the Figs. (3-5). Despite that, the $\mu$ values are clearly below the "threshold" set by European regulation for mortars. The European standard (UNI EN 1015-19: 2000) requires $\mu$ value $\leq 15$ [-] when used as plasters on damp walls. However, it is advisable for mortars to show similar values, or slightly lower, than the masonry under the plaster. Nevertheless, plasters having high permeability to water are suitable in situations where it is essential to ensure breathability to the walls.

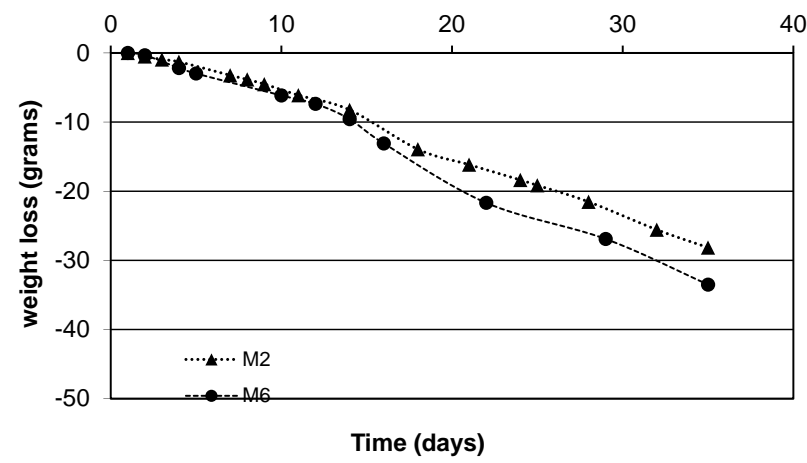

Fig. (5). Water vapor transmission in mortars having the same amount of paper ash/binder ratio ( $\mathrm{pa} / \mathrm{b})$ but different binders (cement and lime: M2, lime and carbon fly ash: M6).

Table 4. Resistance to Water Vapor Transmission of the Mortars $(\boldsymbol{\mu})$

\begin{tabular}{|c|c|}
\hline Mortars & $\boldsymbol{\mu}[-]$ \\
\hline \hline M2 & 7 \\
\hline M3 & 7 \\
\hline M6 & 6 \\
\hline M7 & 5 \\
\hline M8 & 5 \\
\hline
\end{tabular}

\section{CONCLUSIONS}

The present paper focuses on the feasible use of paper ash from paper mills in the construction material sector. In particular, paper ash has been tested as an ingredient in the production of blends for internal or external plaster. For example, in finishing plaster, paper ash can be used as partial or whole replacement of the inert.

The best feature of this material is its lightweight property that gives fresh mortar proper consistency and facilitates its application both by hand (trowel) and by plaster machines. The final product will have low to medium density according to the percentage of the paper ash used in the mixture.

Resistance to vapor transmission, usually a relevant requirement for plasters, is clearly below the "threshold" level set by the European regulation for mortars. According to the values obtained, although slightly scattered, it appears that permeability is supported by the increasing of the paper ash.

The high absorption of water by capillary action, which frequently constitutes a problem in outdoor use, can be modified by treatment with water repellent products. 


\section{ACKNOWLEDGEMENTS}

Authors thank Burgo Group (Mantova plant, Italia) -one of the world's leading producers of coated papers since 2007 [27] - for providing paper mill ashes and the opportunity to publish the preliminary results obtained. Generally, Burgo Group R\&D activity involves their internal structures (laboratories and plants) and external organisations (supplier pilot plants, associations etc.) and various other international research centres.

\section{CONFLICT OF INTEREST}

Declared none.

\section{REFERENCES}

[1] Commission Communication of 21 December 2005, "Taking sustainable use of resources forward: A Thematic Strategy on the prevention and recycling of waste", COM(2005) 666 - Not published in the Official Journal, [on-line]. Available: http://europa.eu/ [Accessed January 2011].

[2] [on-line]. Available: http://www.nisp.org.uk/default.aspx [Accessed the $20^{\text {th }}$ of January 2012].

[3] Decreto Legislativo 3 dicembre 2010 n. 205, "Disposizioni di attuazione della direttiva 2008/98/CE del Parlamento europeo e del Consiglio del 19 novembre 2008", Gazzetta Ufficiale del Parlamento Italiano, n. 288, Supplemento Ordinario n. 269, December 2010.

[4] Decreto Legislativo 3 aprile 2006 n. 152, "Norme in materia ambientale", Gazzetta Ufficiale del Parlamento Italiano, n.88, Supplemento Ordinario n. 96, April 2006.

[5] L. Asquini, E. Furlani, S. Bruckner, and S. Maschio, "Production and characterization of sintered ceramics from paper mill sludge and glass cullet", Chemosphere, vol. 71, pp. 83-89, January 2008.

[6] R. Pöykiö, T. Kuokkanen, and H. Nurmesniemi, "Fly ash from Pulp and Paper Mills: A Potential Soil Amendment and a Forest Fertilizer", In: Pongrácz E, Ed. Proceedings of the Waste Minimization and Resources Use Optimization Conference, University of Oulu, Finland: Oulu University Press, pp. 171-177, June 2004.

[7] A. M. Dunster, "Characterisation of Mineral Wastes, Resources and Processing technologies - Integrated waste management for the production of construction material. Case Study: Paper sludge and paper sludge ash in Portland cement manufacture" WRT 177 / WR0115, 2007. [on-line]. Available: http://www.smartwaste.co.uk/ filelibrary/Portland_cement_paper_sludge.pdf [Accessed the $18^{\text {th }}$ of February 2011].

[8] A. Mohammadi Torkashvand (2010) "The effect of paper mill sludge on chemical properties of acid soil" African Journal of Agricultural Research, vol. 5, no. 22, pp. 3082-3087, 18 November, 2010. [on-line]. Available: http://www.academicjour nals.org/AJAR [Accessed the $18^{\text {th }}$ of February 2011].

[9] J. Gaskin, and L. Morris, "Land Application of Pulp Mill Lime Mud", Research Bulletin, Agricultural Experiment Station, College of Agricultural and Environmental Science, University of Georgia, 2004.

[10] A. Zani, A. Tenaglia, and A. Panigada, "Reimpiego dei fanghi dell'industria cartaria nella produzione dei laterizi", Industria dei laterizi, vol. 34, pp. 326-332, 1992.

[11] C. Marcis, D. Minichelli, S. Bruckner, A. Bachiorrini, and S. Maschio, "Production of monolithic ceramics from incinerated municipal sewage sludge, paper mill sludge and steelworks slag", Ind. Ceramica, vol. 25, pp. 89-95, February 2005.
[12] N. Marchetti, and A. Panigada, "Riutilizzo dei fanghi di cartiera nell'industria dei laterizi", Industria dei laterizi, vol. 34, pp. 279283, 1995.

[13] T.R. Naik, Y. Chun, and R.N. Kraus, "Paper Industry Fibrous Residuals in Concrete and CLSM", Report No. CBU-2005-10, pp. 1-35, November 2005.

[14] T.R. Naik, T. S. Friberg and Y. Chun, "Use of pulp and paper mill residual solids in production of cellucrete", Cement and Concrete Research, vol. 34, pp. 1229-1234, 2004

[15] T.R. Naik, and Y. Chun, "Repulping fibrous residuals from pulp and paper mills for recycling in concrete", Tappi Journal, vol. 3, pp. 7-10, December 2004.

[16] Directive 2004/8/EC of the European Parliament and of the Council of 11 February 2004 on the promotion of cogeneration based on a useful heat demand in the internal energy market and amending Directive 92/42/EEC, Official Journal of the European Parliament L 52, 21/2/2004, February 2004. [on-line]. Available: http://eur-lex.europa.eu/LexUriServ/LexUriServ.do?uri=CELEX:3 2004L0008:en:NOT [Accessed the $15^{\text {th }}$ of June 2011].

[17] [on-line]. Available: http://ec.europa.eu/clima/policies/package/ind ex_en.htm [Accessed the $30^{\text {th }}$ of May 2011].

[18] [on-line]. Available: http://www.cbu.uwm.edu [Accessed the $30^{\text {th }}$ of May 2011].

[19] J. Pera and A. Amrouz, "Development of highly reactive metakaolin from paper sludge", Cement Basic Material, vol. 7, pp. 49-56, March 1998

[20] L. Ernstbrunner, "Rejects from paper manufacture utilized in the cement works", Papier, vol. 51, pp. 284-286, June 1997.

[21] V. Corinaldesi, S. Monosi, F. Tittarelli and O. Favoni, "Influence of paper mill ashes on the properties of self-compacting concrete" Proc. of Tenth ACI International Conference on 'Recent Advances in Concrete Technology and Sustainability Issues', P. Gupta, T.C. Holland, and V.M. Malhotra, Eds. Supplementary Paper, ACI Symposium Publication 261, pp. 587-596, 2009.

[22] Directive 2008/98/EC of the European Parliament and of the Council of 19 November 2008 on waste, Official Journal of the European Parliament L 312, 22/11/2008, pp. 3-30, 2008. [on-line]. Available: http://eur-lex.europa.eu/LexUriServ/LexUriServ.do?uri $=\mathrm{OJ}: \mathrm{L}: 2008: 312: 0003: 0030: \mathrm{en}: \mathrm{PDF}$ [Accessed the $15^{\text {th }}$ of June 2011].

[23] Decreto Ministero Ambiente 3 Agosto 2005, "Definizione dei criteri di ammissibilità dei rifiuti in discarica", Gazzetta Ufficiale del Parlamento Italiano, no. 201, August 2005.

[24] Decreto Ministero Ambiente 5 febbraio 1998, "Individuazione dei rifiuti non pericolosi sottoposti alle procedure semplificate di recupero ai sensi degli articoli 31 e 33 del Decreto Legislativo 5 febbraio, no. 22, 1997 (Identification of non-dangerous wastes undergoing recovery simplified procedure according to articles 31 and 33 in Legislative Decree 5 February 1997 n.22, in Italian)", Gazzetta Ufficiale del Parlamento Italiano, n. 72, Supplemento Ordinario, no. 88, April 1998.

[25] Directive 2006/12/EC of the European Parliament and of the Council of 5 April 2006 on waste, Official Journal of the European Parliament, L 114, pp. 9-21, April 2006. [on-line]. Available: http://eur-

lex.europa.eu/LexUriServ/LexUriServ.do?uri=OJ:L:2006:114:0009 :0021:en:PDF [Accessed the 15 ${ }^{\text {th }}$ June 2011].

[26] G. Fava, V. Corinaldesi, and M.L. Ruello, "Paper mill sludge ash as supplementary cementitious material", Journal of Materials in Civil Engineering vol. 23, June 2011 DOI: 10.1061/(ASCE)MT. 1943-5533.0000218..

[27] [on-line]. Available: http://www.burgo.com/ [Accessed the $18^{\text {th }}$ of February 2011]. 